\title{
El cicle del paper: una proposta didàctica per aproximar-nos a la comprensió del problema dels residus
}

\author{
Alba Castelltort i Valls \\ Agenda 21 Escolar de Barcelona \\ alba.castelltort@campus.uab.es \\ Neus Sanmartí i Puig \\ Dept. Didàctica de la Matemàtiques i les Ciències Experimentals, Facultat d'Educació, UAB \\ neus.sanmarti@uab.es
}

L'article exposa una experiència didàctica que pretén aprofundir en la comprensió de la problemàtica dels residus des de la perspectiva dels cicles. La proposta parteix de la interpretació del cicle del paper per ajudar l'alumnat a reflexionar i comprendre els perquès de la problemàtica del consum de paper i facilitar l'adquisició d'uns sabers que serveixin per explicar la problemàtica d'altres tipologies de residus.

Les activitats d'avaluació realitzades mostren que els alumnes s'apropien d'aquest model amb facilitat, tot i que cal promoure noves activitats d'avaluació per determinar si aquest model perdura o no amb el temps i si promou canvis en les actituds i comportaments envers la prevenció i la separació dels residus.

Aquesta experiència s'ha dut a terme en diverses escoles de Sabadell ja que forma part de les activitats d'educació ambiental del programa "Ciutat i Escola".

Els residus i la seva problemàtica ambiental, són aspectes que molt sovint es treballen des de l'escola ja sigui a través de les diferents àrees, per mitjà d'activitats puntuals o a través de la seva participació en programes d'educació ambiental.

És evident que a l'aula no es poden estudiar totes les problemàtiques ambientals ni tampoc, com en el cas dels residus, es pot estudiar la problemàtica que es genera entorn de cada material que convertim en residu. Tot i aquesta diversitat, existeixen una sèrie de característiques comunes com per exemple, el seu dinamisme al llarg del temps (les problemàtiques actuals no són les mateixes que les de fa uns anys enrere i seran diferents de les futures) i que els seus efectes sovint són difícils de percebre (ja sigui perquè els efectes tenen lloc en altres punts del planeta o perquè es donaran en un futur més o menys proper).

Per aquest motiu cal buscar estratègies didàctiques que permetin comprendre alguns d'aquests problemes i les seves característiques i aconseguir que aquests sabers apresos puguin servir per explicar-ne d'altres.
La proposta que es planteja es basa en afavorir l'aprenentatge d'un coneixement de poques idees però molt nuclears. Un coneixement ben après $i$ que al mateix temps integri valors i habilitats transversals, com per exemple el pensament crític, la capacitat argumentativa i d'escoltar i expressar les idees o l'autonomia, entre altres (Sanmartí, 2004).

Per això s'ha optat per fer una aproximació a la problemàtica dels residus a través de la perspectiva de cicle.

Tal com comenten Márquez i Roca (2001), si considerem la Terra com un conjunt de subsistemes interrelacionats, el concepte de cicle és útil per comprendre alguns dels problemes ambientals que, sota aquesta perspectiva, es poden interpretar com a interrupcions o desequilibris en el funcionament dels cicles naturals o normals de la Terra. Segons aquestes autores, afavorint la representació de processos en forma de cicles a nivell escolar, s'afavoreixen maneres de pensar que van més enllà de les quotidianes, estimulant també la capacitat d'anàlisi i de síntesi. 
A continuació s'exposa com es va dissenyar aquesta proposta partint de la idea del cicle del paper i com aquesta perspectiva no només va afavorir la comprensió de la problemàtica del paper sinó que també estimulava la interpretació de la problemàtica associada als altres residus.

D'altra banda, l'experiència no només es basa en la construcció de nous coneixements (en aquest cas, dels residus) per mitjà de la interpretació i anàlisi de fets, sinó que també pretén que l'alumnat experimenti, que s'emocioni, que expressi i, finalment, que desenvolupi estratègies per actuar d'una manera més responsable, especialment en relació al paper.

\section{El marc teòric de la proposta}

En el disseny de la proposta didàctica, es van tenir en consideració els següents aspectes: les finalitats que es persegueixen en una proposta d'educació ambiental, com s'aprèn i com ensenyar per afavorir aquest aprenentatge.

La proposta educativa, com a activitat d'educació ambiental pretén capacitar per a l'acció individual i col-lectiva a favor del medi. Això no només implica construir uns coneixements (en aquest cas sobre el paper i els seus impactes ambientals) sinó també uns valors, com per exemple la responsabilitat que tenim les persones a l'hora d'adquirir els productes que consumim, la solidaritat envers els països on es manifesten els impactes de la desforestació, etc. També es pretenia desenvolupar la capacitat per actuar, tant en la compra del paper (quin es compra), com en el seu ús (com s'utilitza) i en el destí final que nosaltres li donem (si optem per un tractament finalista o bé pel reciclatge) (fig. 1).

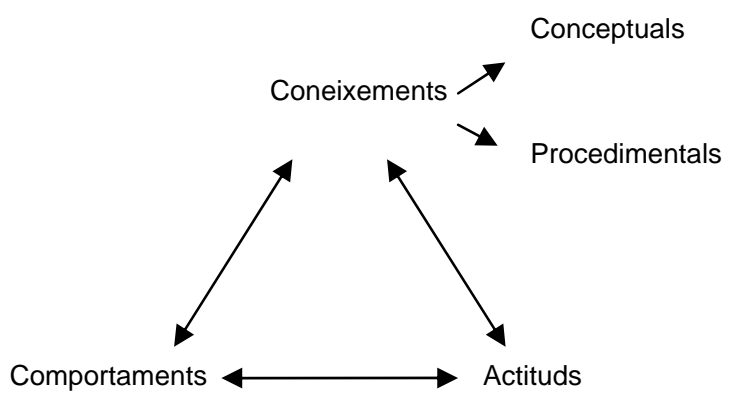

Figura 1. Continguts que hom vol ensenyar. (Font: Sanmartí, N. (1997)).

També s'ha tingut en compte com s'aprèn i per això es parteix de la pròpia experiència dels alumnes (si tenen un bujol per recollir selectivament el paper a la classe, quins tipus de paper utilitzen en un dia, etc.), del saber cultural i social (si creuen que serveix d'alguna cosa separar el paper, si creuen que el paper reciclat té les mateixes qualitats que el paper blanc, etc.), de les emocions, de les interaccions socials i del sistema de raonament.

Finalment, la seqüència didàctica es distribueix al Ilarg del temps seguint el cicle d'aprenentatge amb activitats d'exploració per detectar les idees prèvies de l'alumnat, d'introducció de nous continguts, activitats de síntesi i d'aplicació dels sabers apresos en altres contextos.

\section{La proposta didàctica}

Tenint en compte les idees anteriors, es va dissenyar una proposta didàctica concretada en el cas del paper per a cicle inicial, mitjà i superior de primària. A continuació, s'exposa com es va desenvolupar en el cas de cicle superior i quines van ser les activitats d'avaluació realitzades que van permetre comprovar els aprenentatges de l'alumnat.

La proposta s'iniciava amb una conversa prèvia que partia de la participació dels alumnes en la recollida selectiva de paper a l'aula (qui s'encarrega de buidar el bujol de paper, on es porta desprès, què se'n fa, si el paper blanc es fa de la mateixa manera que el paper reciclat etc.), per desprès identificar els components espacials que formen part del cicle del paper (el bosc, les fàbriques papereres, les fàbriques d'elaboració de fulls, les botigues on els venen, l'escola i els contenidors de recollida selectiva). Posteriorment, s'identificaven els components dinàmics del cicle del paper, és a dir, els fluxos d'energia i matèries (aigua, fusta, paper vell, petroli) que intervenen en tot el cicle del paper (no només en el procés d'elaboració del paper).

Seguidament es plantejava un joc (adaptat de AADD (1995); també es pot trobar a AADD (1999)) on tot el grup-classe participava activament: uns com a representants dels components espacials del cicle, uns altres com a fluxos d'energia i matèries, i la resta com a impactes ambientals del sistema. En el desenvolupament del joc, l'alumnat se situava en cercle i en el mateix ordre seguit en el procés de l'elaboració del paper. Cada representant dels components espacials del cicle exposava la seva funció o tasca que realitzava, explicava allò que necessitava per funcionar i els impactes ambientals que generava. El consum d'energia i de matèries es simbolitzava amb llanes de colors (Ilana blava per l'aigua, negra pel petroli, vermella per l'energia elèctrica) i els impactes ambientals es simbolitzaven col-locant una targeta per cada impacte en el coll de l'alumne que el produïa.

En finalitzar el joc, cada component estava unit per llanes de colors en funció de les seves necessitats i portava penjat al coll, els impactes ambientals produïts. D'aquesta manera es podia identificar d'una manera molt visual (fig. 2) que per produir 
paper no només es necessiten primeres matèries i que els seus impactes ambientals van més enllà de la tala d'arbres. També es podien identificar quines eren les etapes del cicle del paper que produïen més impactes ambientals.

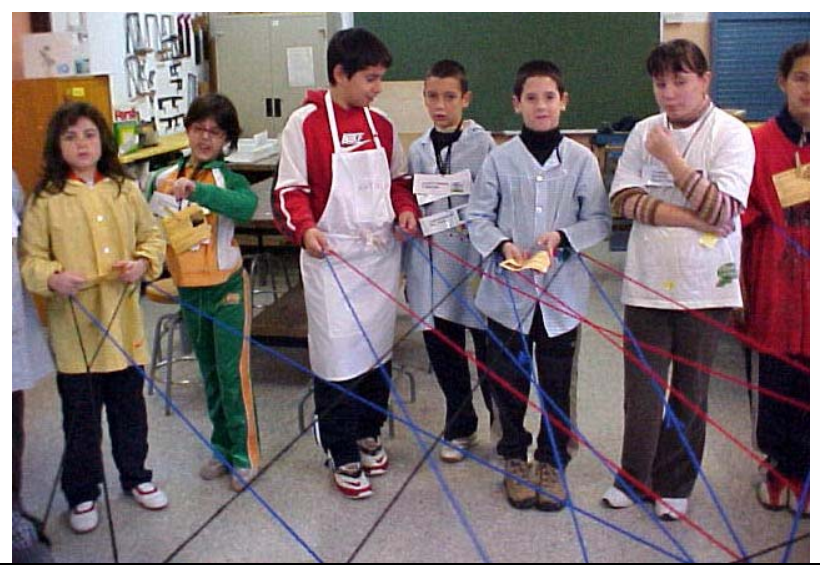

Figura 2. Visualització mitjançant llanes de colors dels consum de matèries primeres i dels impactes ambientals produiits.

A continuació es facilitaven algunes dades (vegeu taula 1) sobre el consum d'aigua, d'energia i de primeres matèries per l'elaboració del paper així com també, algunes dades dels impactes ambientals. Les dades fan referència a la producció de paper blanc i la de paper reciclat i en comparar-les i es feia evident que consumir paper reciclat no només significa reduir espectacularment el consum de fusta sinó també el consum d'aigua i d'energia i amb ells, una reducció dels impactes ambientals.

\begin{tabular}{|l|l|}
\hline \multicolumn{2}{|c|}{ Per fer una tona de... } \\
\hline ...paper nou & ...paper reciclat \\
\hline
\end{tabular}

\section{Es necessita:}

$2400 \mathrm{~kg}$ de fusta (6-12

200.000 litres d'aigua

$7.000 \mathrm{kWh}$ d'energia

elèctrica

\section{Contaminació}

Aigua: elevada

Aire: important

Residus sòlids arbres adults)

\section{Es necessita: \\ Paper vell \\ 20.000 litres d'aigua $2.500 \mathrm{kWh}$ d'energia elèctrica}

\section{Contaminació}

Aigua: moderada

Aire: nul.la o molt baixa

Sense residus

Taula 1. Comparació de matèries primeres i impacte ambiental generat al produir paper nou o reciclat. (Font: Franquesa, T. (dir) (1998) Hàbitat. Guia d'activitats per a l'educació ambiental. Ajuntament de Barcelona).
Desprès d'un petit debat es van comentar estratègies per reduir el consum de paper i per fomentar la seva reutilització i reciclatge. Finalment, es proposava elaborar paper reciclat (fig. 3) com a comprovació d'alguns dels aspectes comentats i com a vivència a recordar.

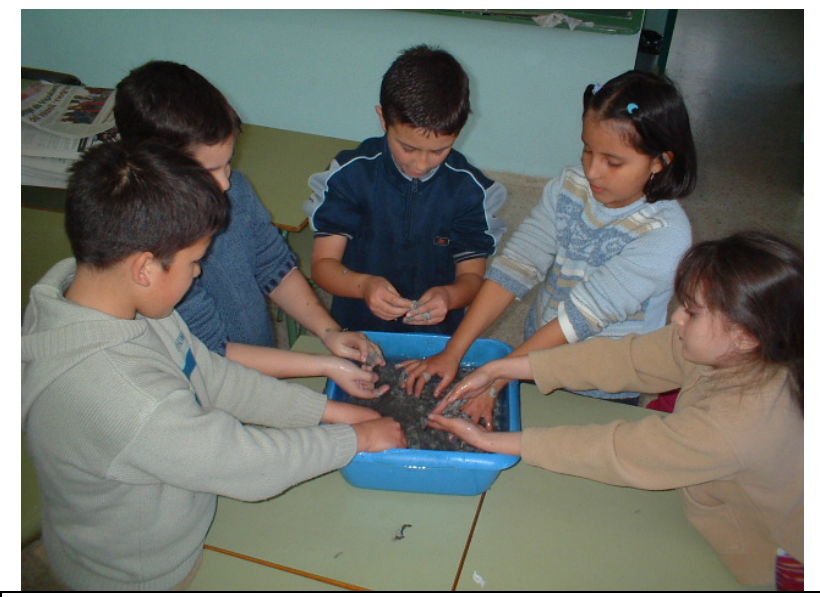

Figura 3. Alumnes en el procés d'elaboració de paper reciclat.

Per avaluar si la proposta afavoria un aprenentatge més significatiu es van utilitzar diferents estratègies:

- Es va demanar a l'alumnat que representés amb un dibuix el recorregut que segueixen les deixalles un cop les dipositem als contenidors del carrer, abans i desprès de realitzar la proposta didàctica presentada.

- En acabar el joc els alumnes van contestar per escrit unes preguntes que tenien com a finalitat sintetitzar algunes de les conclusions més importants extretes del joc.

- Abans de finalitzar la sessió, es va demanar als alumnes si podien explicar el cicle d'altres residus com el vidre o les llaunes.

- El professorat va respondre una enquesta per valorar la proposta didàctica.

\section{Resultats}

Comparant les produccions elaborades pels alumnes abans i desprès de realitzar la proposta didàctica presentada, es va poder constatar que l'activitat afavoria una millor comprensió del recorregut de les deixalles ja que les segones produccions incorporaven nous components.

En concret, es van analitzar les produccions d'una classe de cinquè de primària; es va posar de manifest que abans de realitzar el joc més de la meitat dels alumnes representaven el recorregut 
dels residus de manera poc completa i sense tenir en compte el reciclatge. Desprès de realitzar el joc, totes les noves produccions dels alumnes incorporaven el reciclatge en el cicle dels residus, tot i que algunes continuaven sent més complertes (perquè introduïen els consums d'energia degut al transport o la contaminació) que d'altres.

Les següents produccions (fig. 4) van ser realitzades per una mateixa alumna abans i desprès de la proposta didàctica presentada. En el primer dibuix es pot observar com representa el recorregut de les deixalles incorporant idees que en la realitat no segueixen aquesta seqüència. En canvi, en el segon dibuix la mateixa alumna ha representat el cicle del paper; en aquest cas el concepte de reciclatge hi queda ben representant.

\section{Dibuix previ}
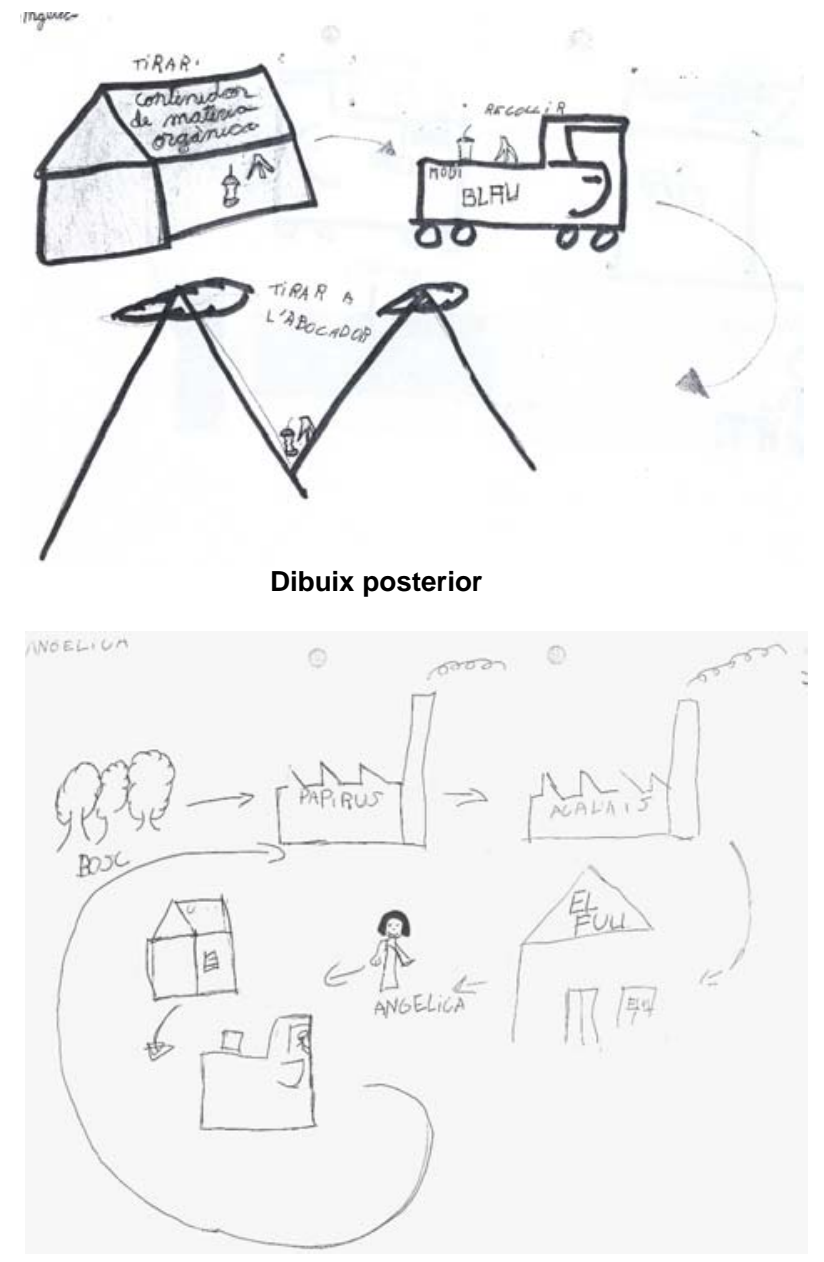

Figura 4. Dos dibuixos de la mateixa alumna, realitzats abans i després respectivament de la seqüència descrita.

D'altra banda, les preguntes que va contestar l'alumnat en finalitzar el joc indicaven que havien identificat la problemàtica associada al gran consum d'aigua i energia que requereix el procés d'elaboració del paper, però en canvi presentaven més dificultats en l'argumentació dels "perquès", així com també en la identificació dels impactes ambientals que produeixen.

En acabar la sessió es comentava oralment si podien explicar el cicle d'altres residus com el vidre o les llaunes i en general. Es detectava que no tenien dificultats per tornar a sistematitzar el procés complet, tot i que sí que en tenien per identificar les matèries primeres que es necessitaven i els impactes ambientals produïts.

Finalment, el professorat va valorar l'activitat mitjançant unes enquestes: en general, la proposta es va valorar com a molt positiva perquè els alumnes participaven activament, perquè era molt visual i perquè facilitava la comprensió de les idees principals. A més a més, molts dels professors van manifestar la voluntat de continuar treballant a l'aula aquests temes.

\section{Reflexions finals}

La proposta didàctica va afavorir una millor comprensió del recorregut de les deixalles i, en concret, una millor comprensió del cicle del paper i la seva problemàtica ambiental. La majoria de l'alumnat incorporava la perspectiva de cicle en les seves segones produccions. En acabar la sessió, l'alumnat no només va ser capaç d'explicar la problemàtica del paper, sinó també de construir arguments per explicar la problemàtica d'altres residus.

La proposta va afavorir actituds de col-laboració en grup i, en alguns casos, l'experiència d'elaborar paper reciclat va contribuir a gestionar certs conflictes entre l'alumnat. A més a més, la proposta va promoure una reflexió sobre la responsabilitat de les persones en el moment de pensar estratègies d'actuació.

Tanmateix, per futures sessions es preveu dissenyar una nova estratègia d'avaluació que permeti:

- identificar els hàbits de consum i ús del paper dels alumnes,

- quantificar de manera sistemàtica si els sabers apresos serveixen per explicar altres residus (en comptes de fer-ho de manera oral),

- si el model del cicle dels residus perdura o no amb el temps. 


\section{Bibliografia}

AADD (1995). Project Wet. Montana: The watercourse an Western Regional Environmental Education Council.

AADD (1999). La contaminación físico-química del agua. Praxis editorial, Barcelona

Franquesa, T., Pujol, R.M., Tarin, R.M., Torras, A. i Sanmartí, N. (1997). L'educació ambiental a l'escola: noves línies de reflexió i actuació. Dossiers Rosa Sensat, 54.

Franquesa, T. (dir) (1998) Hàbitat. Guia d'activitats per a l'educació ambiental. Ajuntament de Barcelona.

Márquez, C. i Roca, M. (2001). El cicle de l'aigua, una altra vegada! Guix, 275, p. 42-48.
Sanmartí, N.(2004). La formació permanent vista des de les didàctiques específiques. A: Batllori, R.; Gómez, A.E.; Oller, M.; Pagès, J. (2004). De la teoria...a l'aula. Formació permanent del professorat $i$ l'ensenyament de les ciències socials. Departament de Didàctica de la Llengua, la Literatura i de les Ciències Socials de la Universitat Autònoma de Barcelona.

Stokking, K.; Aert, L.; Meijberg, W; Kaskens, A. (2003). L'avaluació de l'educació ambiental. Monografies d'Educació Ambiental, 9. Editorial Graó, Societat Balear d'Educació Ambiental, Societat Catalana d'Educació Ambiental, Barcelona.

Aquest treball es va presentar al Simposi sobre l'Ensenyament de les Ciències Naturals de Tortosa, el 2005. 